University of Washington Tacoma

UW Tacoma Digital Commons

3-13-2019

\title{
Knocked Up Knockouts: Pregnancy, Media, and the Sexy Bump
}

Natalie Jolly

University of Washington Tacoma, natjolly@u.washington.edu

Follow this and additional works at: https://digitalcommons.tacoma.uw.edu/ias_pub

\section{Recommended Citation}

Natalie Jolly (2019) Knocked Up Knockouts: Pregnancy, Media, and the Sexy Bump. In Rebecca Lind (Editor) Race/ Gender/ Class/ Media: Considering Diversity Across Audiences, Content, and Producers. Routledge. 4th edition.

This Book Chapter is brought to you for free and open access by the School of Interdisciplinary Arts and Sciences at UW Tacoma Digital Commons. It has been accepted for inclusion in SIAS Faculty Publications by an authorized administrator of UW Tacoma Digital Commons. 


\section{2: Knocked Up Knockouts: Pregnancy, Media, and the Sexy Bump}

Natalie Jolly

Sexy bump imagery in popular culture suggests that a sexualized depiction is becoming incorporated into what we expect of pregnant women, and reflects a new component of normative femininity. How might this frame the expectations we have for women and those that women increasingly have for themselves?

When Beyoncé released her nude pregnancy photos to wild acclaim, the internet had to ask readers if they were still breathing. Indeed, it took only 11 hours for Beyoncé's belly pics to break Instagram's record for the most liked photograph of all time on the photo-sharing platform. Such enthusiastic reception demonstrates how far we've come from the public outrage over Demi Moore’s iconic nude pregnancy shot on the cover of Vanity Fair in August, 1991. Once considered an affront to our cultural sensibilities, the nude pregnant body is now held up as emblematic of all that women have achieved: the symbol that used to conjure body shame now signifies body empowerment. But is this imagery as empowering as we might have hoped?

Beyoncé certainly isn’t alone. This cultural willingness, nay excitement, to celebrate women's pregnant bodies has resulted in the nude pregnancy photoshoot becoming a sort of celebrity rite of passage. Kim and Kourtney Kardashian have both shared full-body nude pregnancy portraits, as has Serena Williams, Jessica Simpson, Britney Spears, Blac Chyna, Mariah Carey, Christina Aguilera, and Claudia Schiffer; truly the list seems endless. Countless women have offered us nude (or nearly so) images of their pregnant bodiesparticularly in the last decade. Spanning social media, print media, and big and small screens, these images seem to suggest that womanhood has become so synonymous with sexual desirability that even pregnant women are sexy now. Drawing on both a discussion of celebrity trends and an analysis of everyday photos posted to Instagram with the hashtag 
\#pregnancyphotoshoot, I consider whether this imagery creates a space for pregnant women to feel sexy and sexual, or reflects a move to sexualize moments - such as pregnancy - that had until now remained largely asexual.

\section{Sexy Lady: Gender Norms, Femininity, and Hypersexuality}

Femininity, and gender more generally, is not thought to be something that you have, but rather something that you do. Indeed all of us are taught to understand what appropriate femininity looks like (in terms of suitable behaviors, interests, skills, bodies, practices) in our society. Sociologists understand gender as a cultural phenomenon (Williams \& Best, 1982), learned through an ongoing process of socialization; socializing agents include parents, peers, schools, and of course media. The media imagery we consume serves as an instruction manual of sorts, and teaches us how to properly perform gender and conform to the gender norms established by our society.

One aspect of gender performance that has gained scholars' attention is how representations of women seem increasingly to depict them in sexualized or sexually objectified ways. For example, Gill (2007, p. 81) argued that "Increasingly all representations of women in adverts are being refracted through sexually objectifying imagery” (emphasis in original). Hatton and Trautner (2011) analyzed more than 40 years of Rolling Stone magazine covers (1967-2009), and concluded that sexualized images of both men and women have increased in recent decades, but women continue to be more frequently sexualized than men. Their most striking finding was that women—but not men—are increasingly likely to be hypersexualized, or displayed in highly sexual ways, including being fully naked, exhibiting explicitly sexual touching (by oneself or someone else), being overtly posed for sexual activity, or otherwise drawing attention to breasts/chest, genitals, and/or buttocks. 
As a result of numerous similar findings, media scholars argue that women's sexualization has become almost invisible by virtue of its very ubiquity. Most agree that popular culture has become raunch (Levy, 2005) or pornified (Attwood, 2006; Paul, 2006), referring to the relatively wide range of highly sexualized "visual representational practices and products across popular culture, encompassing more or less explicit representations of bodies, and sexuality in advertising, music videos and mainstream entertainments” (Mulholland, 2015, p. 2). Consequently, women and men don’t need to look at sexually explicit material to be profoundly affected by it; these images, representations, and messages are now directly delivered to us via mainstream media (Dines, 2010). As this imagery becomes more familiar, it begins to seem normal, and normative - a required component of our gender expectations for women.

As a result, women (and men) begin to see hypersexual depictions of women as culturally desirable, and indeed perhaps an obligatory component of femininity (Griffin, 2004). This norm has begun to shape the representation of women in contexts ranging from sports (Weaving, 2012) to politics (Doan, 2011). Indeed, these norms have long tentacles, and seem to reach all the way to how women are represented in pregnancy.

\section{Hot Mamas and the Rise of the Sexy Bump}

The 2015 film Mad Max: Fury Road was widely recognized as a feminist victory, not least for its depiction of The Wives, the harem of five diaphanous clad beauties whose daring escape serves as the movie's central plot. Central to this narrative was the story of the favorite wife, named The Splendid Angharad, whose visibly pregnant body is used to great effect as both shield and prize. A scene that likely lodges in viewers' minds depicts Splendid seductively spraying water over her pregnant belly (and gauzy clothing) in what can only be reminiscent of a wet T-shirt contest. The strategically spilled water rendered more than just Splendid's clothing 
transparent; in this scene (and others like it) we can begin to see that pregnant women are no longer restricted to asexual depictions.

The pregnant belly was not always front and center in media representations of expecting women. In the 1950s, CBS deemed even the word "pregnant” too scandalous to say on television, leaving Lucy to comedically explore several euphemisms for her, ahem, “condition” during the second season of I Love Lucy. Such is hardly the case now, and the nude pregnant belly makes a cameo in television shows ranging from Friends to Charmed to Jane the Virgin to Modern Family to Game of Thrones, and imagery that depicts a fully nude and visibly pregnant body is becoming more prevalent. The HBO hit sitcom Girls, for example, offers us a fully naked Caroline ${ }^{1}$ writhing in the bathtub. The Starz drama Outlander continues the action, and showcases a pregnant (and topless) Claire as she actively engages in steamy sex while sporting a visibly bared (prosthetic) belly. Interestingly, popular discussion of (and viewer response to) these episodes was largely positive; people congratulated these shows for breaking Hollywood's last taboo (Jolly, 2017) against explicitly sexualized depictions of pregnant women. So before we put this sexy bump imagery to bed, so to speak, perhaps we need to consider whether these sexually explicit depictions of pregnancy are actually empowering for women?

\section{The Yummy Mummy, the Momshell, the MILF, and other Aspirational Women}

The rise of the sexy bump imagery suggests there remains something to be gained in sexualizing the pregnant body. Conventional pregnancy imagery was staunchly devoid of sexuality and certainly left no room for discussions of women's experience (or enjoyment) of sex, nor did it consider pregnant women to be sexually desirable. In this regard, sexy bump imagery challenges conventional gender norms that reduced pregnant women to frumpy and unattractive caricatures of their formerly beautiful selves. These sexy bumps, from Beyoncé to 
Splendid, certainly suggest that there is - finally - a cultural appreciation for (and indeed celebration of) women's pregnant bodies. After a media diet so heavily dominated by women's waifish figures, these full-bellied beauties make for a fine feast. Might this constitute a “democratization of desire” (McNair, 2002, p. 11), and result in a more diverse and pluralistic sexual culture than we have traditionally experienced? Certainly this new trend in representation has demonstrated that it is not just thin, White bodies that are feminine, beautiful and desirable. It has opened the door for audiences to see pregnant women of color depicted as gorgeous goddesses, and has similarly positioned those with athletic, curvy, or otherwise nonconventionally feminine bodies as beautiful, sexy, and desirable.

Nothing is wrong with that, to be sure. It's certainly time to challenge the assumption that the pregnant body is ugly, undesirable, and asexual, and perhaps this sexy bump imagery may be one way to accomplish this. However, as of yet, it appears that the empowering potential of this imagery has yet to be fully achieved. although the sexy bump imagery seems to expand the range of bodies we see, it does not yet seem to make good on the promise of democratizing our shared desire. It may also foreclose women's empowerment by reinforcing the idea that women's power is still largely tied to whether her culture sees her body as desirable, or sexy, or hot. The problem seems to be one of homogenization: increasingly, sexy media portrayals of women are not a type of depiction, but are the only way that women (even pregnant women) are portrayed. This imagery suggests a corresponding narrowing of socially acceptable ways of doing femininity, meaning that women are increasingly sanctioned for not performing gender in sociallyappropriate (read: hypersexualized) ways. In particular, non-normative or non-dominant displays of femininity or sexuality are rarely visible in popular depictions of pregnancy. This is not to say that women are powerless to ignore these social pressures, but merely to suggest that there are 
fewer culturally available alternatives available to women as they navigate the norms of femininity. Sexy bump imagery serves to further strengthen one of our culture's most muscular myths - that a woman's desirability is her most significant asset.

\section{Everyday Sexy Bumps on Instagram: \#Pregnancyphotoshoot}

I conducted a qualitative review of 200 images posted to Instagram using the hashtag \#pregnancyphotoshoot ${ }^{2}$, and my findings suggest that women have been influenced by the norms transmitted by the media's sexy bump imagery. Of the images I reviewed, 10\% featured a visibly nude pregnant belly, a further seven percent of the images depicted women in transparent clothing or posed in a nude silhouette, and another $10 \%$ of the women revealed bare legs, shoulders, and/or chest/breast. About five percent of the images I reviewed qualified as hypersexual -- they included multiple of the above attributes (e.g. transparent clothing as well as a bare belly and chest). I found that women were depicted in sexualized ways in nearly one-third of Instagram’s \#pregnancyphotoshoot images. Images of nude pregnant women (whether soaking in baths of milk and rose petals, wearing shirts strategically unbuttoned to showcase bared bellies, or swathed in diaphanous fabric revealing silhouettes of legs, thighs, and buttocks) imply that even everyday pregnancy photos include sexually suggestive depictions of women's bodies. These images echo the highly glamorized photographs offered by celebrities, and fuse sexual availability and desirability to conventional gender norms. Now, it would seem, it is not enough to have a conventionally slender body or to have a conventionally beautiful face. Pregnant women (and women more generally) must also incorporate this new aspect of sexual desirability into what it is to be conventionally feminine. The images of nude pregnant celebrities seem to be serving as a blueprint for how women in society now do femininity. 
Will women find that these images expand the model of femininity during pregnancy and allow them to be sexual and sexually desirable? Will women feel increasing pressure to perform a socially-appropriate heteronormative version of sexy during their pregnancy? Will they be socially sanctioned for not doing so? Women experience their culture in myriad ways, and we are all caught in the complicated choreographies of navigating social norms. But over time, expectations of how women should look - even when they are pregnant - get baked in and shape our very assumptions about the social world and our place in it.

Sociology has long reminded us that “how we ‘see’ ourselves and our social relations matters, because it enters into and informs our actions and practices” (Hall, 2000, p 272). One specific consequence of the rise of hypersexualized imagery is that women increasingly see their bodies from a third-person perspective. Such a focus on observable traits - "How do I look?" displaces a focus on a first-person perspective focused on questions such as "How do I feel?” or "What am I capable of?" This emphasis reinforces the prevailing cultural message that what a woman's body looks like is more important than what a woman's body can do; it reinforces a perception of woman as object rather than subject. Not every woman in America will become pregnant and have a child, but most will; pregnancy and childbirth are one of the many things that many women do with their bodies. Certainly during pregnancy (and subsequently during childbirth and early mothering) a first-person focus is beneficial as women take on the physically-taxing labor associated with delivery and early mothering. More generally, too, a first-person perspective encourages women to divest from our culture's pervasive desire to reduce a woman's worth to the degree to which her body conforms to prevailing social norms. Since when did being (and remaining) sexually desirable become the only long game for women? 
Society shapes us, mind and body. Social norms have the power to shape how we experience and relate to our bodies in real and consequential ways. Imagery such as the sexy bump can serve to normalize assumptions about women and their bodies, and imply that hypersexuality is an integral component of femininity. Through the seamless representation of hypersexualized imagery across multiple media platforms - from celebrity posts to everyday Instagram pictures - we are reminded of the pervasive gender norms that gird our society. Media imagery does matter; this imagery, and the social norms that images telegraph, both produce and constrain the experiences that we have and the seemingly personal choices that we make. They further construct a one-dimensional version of femininity and heterosexuality as a universal norm. For a woman, this can mean that her experience of pregnancy is now shaped by a cultural climate that expects her to always be sexy, available, consumable, and hot. And although this may create a new opportunity to feel sexual during a time that has long been seen as asexual, it nonetheless reinforces the prevailing cultural message that what her body looks like is more important than what her body can do. Such messaging fuels a social norm that frames the expectations we have for women, and those that women increasingly have for themselves.

\section{Notes}

1. Gaby Hoffman, who plays the character in Girls, was seven months pregnant at the time, so her belly was real.

2. Our cultural celebration of what we call "the bump" is a relatively new phenomenon. Until fairly recently, pregnancy was something to be hidden. Maternity clothes strove to disguise rather than accentuate a woman's pregnancy. Now we have a culture in which the very existence of the hashtag \#pregnancyphotoshoot is just one example of the increased visibility and deification of the pregnant body. 


\section{It's Your Turn: What Do You Think? What Will You Find?}

1. Locate the pregnancy images of 5 of the celebrities mentioned here. Describe where these images appeared (social media, magazine cover, website) and discuss similarities and differences across the images. Consider the details of each image (clothing, pose, setting, positioning, facial expression and gaze, and so forth) and locate patterns that appear across several of your images. To what extent and how might any similarities transmit or reflect social norms? To what extent and how might any differences represent a democratization of desire?

2. Use an online search feature to compare maternity fashion from the 1950s to the maternity fashion of today. What are some differences and similarities you see over time? What observations can you make about gender norms during each era, given popular maternity styles of the day? How might fashion trends serve to reinforce prevailing social norms?

3. Working in groups, locate 7-10 magazines whose covers you think depict women in empowering ways. Describe the women and what warranted their appearance on the cover. What similarities and differences do you see? Consider the details of each image (as above) and consider whether any patterns you might identify might reinforce or challenge social norms.

4. Conduct your own analysis of images shared using the \#pregnancyphotoshoot hashtag. How are the patterns you identify similar to or different from what the author noted? In what ways do you think the images reinforce or challenge gender norms?

5. Investigate public response to online media depictions of a current celebrity who was recently pregnant. Note whether the photo was posted by the celebrity herself on social media or posted by a media outlet (e.g., magazine). Did the photo seem to be taken by a paparazzo? Analyze how the woman was depicted (as above), and then look at the public's reaction to this imagery (are the comments generally positive, mixed, generally negative). What does this tell 
you about gender norms? Note also how the woman's race ties into the public's response, to reflect or challenge the normativity of Whiteness or - if the celebrity is a woman of color - to reflect or challenge implicit or explicit racism?

\section{References}

Attwood, F. (2006). Sexed up: Theorising the sexualisation of culture. Sexualities. 9(1). 16-77. Dines, G. (2010). Pornland: How porn has hijacked our sexuality. Boston, MA: Beacon Press. Doan, A. (2011). What's wrong with being sexy? Why political science needs to get serious about sexuality. PS: Political Science and Politics, 44(1), 31-34.

Gill, R. (2007). Gender and the media. Cambridge, UK: Polity Press.

Griffin, C. (2004). Good girls, bad girls: Anglocentrism and diversity in the constitution of contemporary girlhood. In: A. Harris, (Ed). All about the girl: Culture, power, and identity. (pp. 29-44). London: Routledge.

Hall, S. (2000) Racist ideologies and the media. In P. Marris \& S. Thornham, (Eds.) Media studies: A reader. (2 ${ }^{\text {nd }}$ ed.). (pp. 271-282). New York: New York University Press.

Hatton, E. \& Trautner, M. N. (2011). Equal opportunity objectification? The sexualization of men and women on the Cover of Rolling Stone. Sexuality \& Culture. 15 (3): pp 256-278.

Jolly, N. (2017). Sexy birth: Breaking Hollywood's last taboo. Sexualities. 23(1).

Levy, A. (2005). Female chauvinist pigs: Women and the rise of raunch culture. Melbourne: Schwartz Publishing.

McNair, B. (2002). Striptease culture: Sex media and the democratisation of desire. London: Routledge.

Mulholland, M. (2015). Walking a fine line: Young people negotiate pornified heterosex. Sexualities, 18(5-6), 731-749. 
Paul, P. (2006). Pornified: How pornography is damaging our lives, our relationships and our families. New York: Time Books.

Weaving, C. (2012). Smoke and mirrors: A feminist critique of women Olympians’ nude reflections. Sport Ethics and Philosophy, 6(2). 232-250.

Williams, J. E., \& Best, D. L. (1982). Measuring sex stereotypes: A thirty nation study. Newbury Park, CA: Sage. 